$\mathbf{R}_{\text {ESeA }}^{\text {RCH }}$ RTICLe

\section{Histomorphological and histochemical studies on infundibulum of oviduct in Japanease quails}

\author{
P. N. Thakur, P. J. Kapadnis ${ }^{1}$ and N. M. Karad ${ }^{1}$
}

Members of the Research Forum Associate Author :

${ }^{1}$ Department of Veterinary Anatomy, College of Veterinary and Animal Sciences, Parbhani (M.S.) India

AUTHOR FOR CORRESPONDENCE : P. N. Thakur,

Department of Veterinary Anatomy, College of Veterinary and Animal Sciences, Parbhani (M.S.) India

Email : pravin_thakur75@

rediffmail.com
Abstract : The mucosa of Isthumus presented lamina epithelialis, lamina propria and lamina mucosae. The mucosa was thrown into folds viz., primary and secondary folds. The lamina epithelialis presented simple columnar ciliated epithelium in pseudostratified columnar ciliated epithelium was observed in isthmus in both the groups of quail.

Key words : Histomorphology, Histochemistry infundibulum, Oviduct, Japanease quail

How to cite this paper : Thakur, P.N., Kapadnis, P.J. and Karad, N.M. (2019). Histomorphological and histochemical studies on infundibulum of oviduct in Japanease quails. Vet. Sci. Res. J., 10(1) : 22-26, DOI : 10.15740/HAS/VSRJ/10.1/22-26. Copyright@2019: Hind Agri-Horticultural Society.

Paper History : Received : 08.02.2019; Revised : 18.03.2019; Accepted : 25.03 .2019 